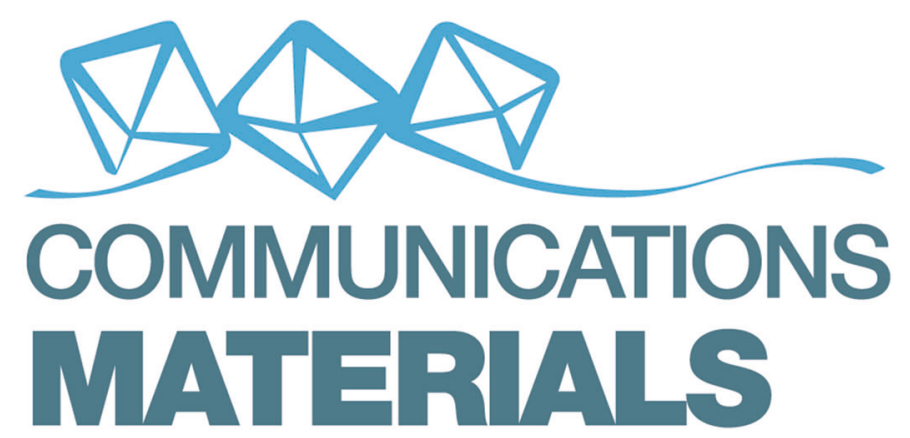

EDITORIAL

OPEN

\title{
Welcome to Communications Materials
}

\author{
A collaboration with the materials community
}

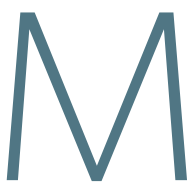

aterials science as a subject is a relative infant in comparison to the disciplines that birthed it: biology, chemistry, engineering and physics. Yet while the title of 'materials science' was adopted later than for those subjects, the study of materials is one of the oldest scientific pursuits. Moreover, materials science is expected to provide solutions to some of the key challenges facing society, including those related to energy, healthcare, and transportation. It is therefore not surprising that materials science and engineering has emerged as a highly active and wellfunded discipline. Indeed, this was one of the motivations for the launch of Nature Materials and it is similar logic that now leads to the launch of Communications Materials. In this Editorial we hope to convey to you our vision for the journal and what we believe makes us unique.

We aim to maximize the visibility of the works we publish, aided by three key points: selectivity, broad scope and open access. We will publish papers that are important advances for researchers working on a particular topic. In particular, papers in our journal must present something that will interest other specialists. That point of interest might be new fundamental understanding, performance improvement, important applications demonstrations, promising techniques and methodologies, valuable data sets, to name a few. Furthermore, combining selectivity with a broad-scope -spanning all of materials science, including topics at the interface with biology, chemistry and physics-makes Communications Materials a great forum for researchers wanting to communicate findings that might be of interest beyond their immediate community. It is important to note that achieving materials that will benefit society requires intimate knowledge of their basic physics, chemistry and biological interactions, all the way to how they might be processed and scaled-up. We therefore aim to publish works across all Technology Readiness Levels, as well as wider issues related to materials sustainability and economics. And our open access publishing model will ensure that these interesting advances are read by as many people as possible, enabling future works to build on them.

Key to achieving the above editorial and publishing goals is our editorial model. We combine an in-house editorial team with an external Editorial Board; editorial decision making and peer review will be performed by both in-house and external editors. This collaboration allows us to marry together the subject-specific knowledge of active researchers with the editorial know-how of professional editors, helping us to publish works that will interest our readers, with a fair and productive editorial process for our authors and referees. We have started to recruit the first scientists to our Editorial Board and we will be expanding the team as the journal grows in number and breadth of submissions. We are particularly passionate about ensuring that our Editorial Board demonstrates the diversity of the research community, such as significant representation from earlycareer researchers, gender balance and geographic diversity. We are equally passionate that each and every Editorial Board Member plays an active role in editorial decision making.

Nature Research journals as a whole are taking increasingly large steps to move away from the traditional 'black-box' 
model of peer review and Communications Materials aims to further these initiatives. Our sister journals-Communications Biology, Communications Chemistry and Communications Physics-have all followed Nature Communications' example in giving authors the choice to publish reviewer reports and author reply letters. We call this Transparent Peer Review. Communications Materials will additionally publish journal decision letters in a Peer Review File, on an author opt-in basis. A substantial amount of information is transferred between authors, referees and editors during peer review, some of which provides insight into the science of a paper. Publishing our decision letters will also give readers insight regarding the path a paper has taken through peer review, including an editor's handling of a sub- mission, decision dates beyond final acceptance and number of rounds of review. We encourage our authors to optin to Transparent Peer Review, when they feel comfortable doing so.

The above hopefully gives a sense for where we see Communications Materials heading and how the journal might contribute to the materials community. We are deeply excited about this collaborative project and thoroughly look forward to the many ways the journal will interact and work alongside materials researchers, as authors, referees and editors. Finally, we invite you to read the first research papers that accompany this Editorial, and look forward to extending the breadth of our content in the coming days, weeks and years.
Published online: 04 February 2020

\begin{abstract}
(c) (i) Open Access This article is licensed under a Creative Commons Attribution 4.0 International License, which permits use, sharing, adaptation, distribution and reproduction in any medium or format, as long as you give appropriate credit to the original author(s) and the source, provide a link to the Creative Commons license, and indicate if changes were made. The images or other third party material in this article are included in the article's Creative Commons license, unless indicated otherwise in a credit line to the material. If material is not included in the article's Creative Commons license and your intended use is not permitted by statutory regulation or exceeds the permitted use, you will need to obtain permission directly from the copyright holder. To view a copy of this license, visit http:// creativecommons.org/licenses/by/4.0/.
\end{abstract}

(c) Springer Nature Limited 2020 